\title{
Analysis of Occupational Noise in Association with Blood Pressure Among Workers at Geothermal Power Plant
}

\author{
Muhyidin $^{1 *}$, Sjahrul Meizar Nasri ${ }^{1}$
}

Program Study Magister of Occupational Health and Safety, Faculty of Public Health, Universitas Indonesia

*Corresponding author, e-mail: muhyi.bintan@gmail.com

\section{(i) (2)}

\section{Abstract}

The purpose of this study will analyze noise intensity at a geothermal power plant and its association with employees' blood pressure and risk of hypertension. A cross-sectional survey using questionnaire as primary data; noise dosimeter, body mass index and blood pressure measurement records as secondary data. Total 101 workers participated by purposive sampling based on a similar exposure group (SEG). Mann-Whitney \& $\chi^{2}$ test analysis was applied to examine the association of dependent variables and independent variables. Noise intensity was measured from the noise dose result during 8 working hours. Subjects with noise dose $>8 \mathrm{o}$ dBA had higher levels of SBP / systolic blood pressure (119.1 $\pm 11.2 \mathrm{mmHg}$ ) and DBP / diastolic blood pressure (75.6 \pm 5.3 ) than subjects with noise dose $\leq 80 \mathrm{dBA}$ (SBP: $117.9 \pm 6.6 \mathrm{mmHg}$, DBP: $75.0 \pm 5.1$. The hypertension prevalence was $7.9 \%$ at participants with noise dose $>80 \mathrm{dBA}$ and $2.6 \%$ in noise dose $\leq 8 \mathrm{o} \mathrm{dBA}$. The odds ratio (OR) of noise dose $>8 \mathrm{o} \mathrm{dBA}(\mathrm{OR}=3.190,95 \% \mathrm{CI}=0.358-28.394$ ), and smoking ( $\mathrm{OR}=2.469,95 \% \mathrm{CI}=0.416-14.645)$. Noise intensity was not associated with SBP (p-value = $0.664)$, DBP ( $\mathrm{p}$-value $=0.538)$, and hypertension $(\mathrm{p}$-value $=0.405)$. This study was the pioneer in the geothermal industry with noise dosimetry measurement. Further comprehensive studies need to be conducted to confirm the association between noise intensity and blood pressure and the risk of hypertension.

Keywords: blood pressure; geothermal power plant; hypertension; occupational noise

\section{Introduction}

Indonesia has geothermal resources with a potential of 29 Gigawatt (GW), and it is the most significant geothermal potential in the world. Indonesia is the $2^{\text {nd }}$ largest of geothermal producers with a total installed capacity of 2,130.7 Megawatt (MW) as of 2020. The entire primary energy mix from renewable energy resources is $11.2 \%$ with an installed capacity of $10.4 \mathrm{GW}$ and contributed to 64.4 million tons of carbon dioxide $\left(\mathrm{CO}_{2}\right)$ emission reduction. Geothermal contributed $20.49 \%$ of total renewable energy resources (Ditjen EBTKE, 2021). By 2025, the government of Indonesia target to have $23 \%$ of the primary energy mix is from renewable energy (including geothermal) and some regulations \& policies were established to promote the development of clean energy.

The geothermal power plant has a high noise level starting from the drilling process, steam flow, well logging, maintenance process and during regular operation such as a power plant area. PT X is a geothermal power plant company in West Java province, Indonesia. Production equipment with highlevel noise $>85 \mathrm{dBA}$ includes steam turbines, generators, condenser, suitable hot pumps, auxiliary pumps, 
and compressors running during regular operation. Another noise source was steam flow at the good pad, steam pipeline, and interface area. Many studies showed that noise hazards have an auditory and nonauditory impact. The aural impact includes noise-induced hearing loss (NIHL), tinnitus, and temporary/permanent threshold shift. At the same time, non-auditory impacts are an annoyance, cardiovascular disease (including hypertension), cognitive performance, sleep disturbance, stress, and communication disturbance (Basner et al., 2014; Sheppard et al., 2020; Munzel et al., 2016).

Previous studies showed that noise exposure was associated with the increased risk of hypertension and cardiovascular disease, digestive disorders, and sleep disorders (Chen et al., 2017). A study in South Korea showed that from 107,407 noise-exposed workers $>85$ dBA had OR 1.42 than 152,790 non-exposed workers to have hypertension (Kim \& Ahn, 2021). Workers exposed to noise $>80 \mathrm{dBA}$ had a higher risk of hypertension and increased blood pressure (Chang et al., 2012). Another study showed occupational noise level 75-85 dBA increased hypertension risk ( $\mathrm{OR} 1.56,95 \% \mathrm{CI}=1.13-2.17$ ) and noise level $\geq 85 \mathrm{dBA}$ with OR 1.58 compared to noise level $\leq 75 \mathrm{dBA}$ (De Souza et al., 2015). Many studies on noise exposure and the association with SBP, DBP, and /or hypertension were conducted, but the results were not always consistent (Chen et al., 2017). No study yet on the noise intensity associated with blood pressure in the geothermal power plant industry. The novelty of this study was the noise dose measurement based on 8 working hours based on the SEG at the geothermal power plant. It will reflect the actual noise exposure to workers. This study investigates the association between noise intensity and workers' blood pressure and the risk of hypertension.

\section{Methods \\ 2.1 Data Collection}

This cross-sectional study had 101 respondents who participated in a geothermal power plant in West Java, Indonesia. The sampling method was purposive sampling from a total of 103 permanent employees. Contractor employees were not sampled due to study limitations. The average 461 contractor employees were not staying permanently at the site (based on contract period and some on an on-call basis). The company did not keep the contractor's medical checkup records. Minimum sample based on the formula $\mathrm{n}=\mathrm{Z}^{2}(1-\alpha / 2) \cdot \mathrm{P}(1-\mathrm{P}) / \mathrm{d}^{2}=(1,96)^{2} \cdot 0,5(1-0,5) /(0,1)^{2}=96$ samples. The $\mathrm{Z}$ value based on the $\alpha=$ $5 \%$ and $\mathrm{P}$ was the proportion case studied in the population (due to no data proportion of hypertension case at geothermal industry, the proportion value was $50 \%$ to get the number of samples maximal, and $\mathrm{d}$ was precision (Prasetyo and Ariawan, 2008). The inclusion criteria for the sample participants were permanent employees at a geothermal power plant in the field with a minimum service year was 6 months. In contrast, exclusion criteria were contractor, vendor, visitors, and geothermal employees at head office Jakarta.

Primary data was taken by questionnaire to gather data on age, sex, service year, smoking habit, and stress level. Informed consent was explained before participants responded to the questionnaire. The secondary data was taken from the company on noise intensity and MCU / medical checkups (SBP, DBP, and body mass index). Noise dosimeter type Noisepro DLX-1 Dosimeter measured noise intensity for 8 working hours to a similar exposure group (SEG) 2020 and 2021 by an accredited third party. There were 5 SEGs with nine noise dose samples taken for this study. The stress level was measured by the work stress diagnostic survey from the Ministry of Manpower Republic of Indonesia No.5 years 2018. This survey consists of 30 questions based on a Likert scale with a value of 1-7. Validity and reliability analysis was performed to ensure the data gathered were valid and reliable.

\subsection{Data Analysis}

The normality of SBP and DBP data distribution was analyzed with frequency distribution, Kolmogorov-Smirnov, and Shapiro-Wilk test. Kolmogorov-Smirnov and Shapiro-Wilk tests were used to check data normality distribution, and if the significance levels were $>0.05$, then the data was expected. 
Shapiro-Wilk test can be used for sample size less than 50 (also can be used for larger sample size) and has more statistical power to detect normality data than Kolmogorov-Smirnov test (Barton \& Peat, 2014). Table 1 showed both Kolmogorov-Smirnov and Shapiro-Wilk tests had significance levels (Sig. value = o.ooo). It means the SBP and DBP were non-normal data distribution, and Mann-Whitney analysis calculated the p-value.

Mann-Whitney test was used for non-normal data distribution and conducted to calculate the $\mathrm{p}$ value of categorical independent variables (noise intensity, age, sex, service year, smoking, body mass index and stress level) and numerical dependent variables SBP and DBP. $\chi^{2}$ test was conducted for categorical variables to examine the association between personal characteristics as an independent variable and hypertension as the dependent variable. The odds ratio (OR) was calculated to get hypertension risk at a $95 \%$ confidence interval (CI). All statistical analysis in this study using software IBM SPSS Statistics 24 for Windows.

\section{Result}

Majority of subjects, $62.4 \%(n=63)$ were exposed to noise $>80 \mathrm{dBA}$. Exposed subject to noise intensity $>80 \mathrm{dBA}$ had higher SBP and DBP levels than $\leq 80 \mathrm{dBA}$ noise exposure. There was no association between noise intensity and SBP $(\mathrm{p}$-value $=0.664)$ and DBP $(\mathrm{p}$-value $=0.538)$. Subjects with age $>40$ years old had higher SBP \& DBP level compared to subjects with age $\leq 40$ years old and no association between age and SBP ( $\mathrm{p}$-value $=0.157$ ) and DBP ( $\mathrm{p}$-value $=0.328)$. Majority of subjects were male, $96 \%$ $(\mathrm{n}=97)$ had higher SBP \& DBP level than female. There were $41.6 \%$ with service year $>15$ years with no association between service years and SBP $(p$-value $=0.141)$ and DBP $(p$-value $=0.259)$. Subjects with smoking habits had higher SBP \& DBP levels than a non - smoking participants. Average SBP level (121.6 \pm 9.6$)$ and SBP level (77.4 \pm 4.5$)$ with obese category was higher than normal weight and overweight category with no association between body mass index (BMI) with SBP (p-value $=0.073$ ) and DBP (pvalue $=0.08)$. Subjects with the severe stress level category had higher SBP and DBP levels (119.6 \pm 10.2 and 75.9 \pm 5 ) than the mild and medium categories. Detail Kolmogorov-Smirnov and Shapiro-Wilk test results were in Table 1, and frequency distribution of variables and association with SBP and DBP was shown in Table 2.

Table 1. Kolmogorov-Smirnov test result

\begin{tabular}{|c|c|c|c|c|c|c|}
\hline & \multicolumn{3}{|c|}{ Kolmogorov-Smirnov ${ }^{a}$} & \multicolumn{3}{|c|}{ Shapiro-Wilk } \\
\hline & Statistic & df & Sig. & Statistic & df & Sig. \\
\hline SBP (systolic blood pressure) & 0.305 & 101 & 0.000 & 0.825 & 101 & 0.000 \\
\hline DBP (diastolic blood pressure) & 0.359 & 101 & 0.000 & 0.668 & 101 & 0.000 \\
\hline
\end{tabular}

a. Lilliefors significance correction

Table 2. Frequency distribution of personal characteristics, SBP and DBP

\begin{tabular}{|c|c|c|c|c|c|}
\hline \multirow[t]{2}{*}{ Variables } & \multirow[t]{2}{*}{$\mathbf{n}$} & \multicolumn{2}{|c|}{ SBP } & \multicolumn{2}{|c|}{ DBP } \\
\hline & & Mean \pm SD & P-value* & $\operatorname{Mean} \pm S D$ & P-value * \\
\hline \multicolumn{6}{|l|}{ Noise intensity } \\
\hline$\leq 80 \mathrm{dBA}$ & $38(37.6)$ & $117 \cdot 9 \pm 6.6$ & 0.664 & $75.0 \pm 5.1$ & 0.538 \\
\hline$>80 \mathrm{dBA}$ & $63(62.4)$ & $119.1 \pm 11.2$ & & $75 \cdot 6 \pm 5 \cdot 3$ & \\
\hline \multicolumn{6}{|l|}{ Age } \\
\hline$\leq 40$ years old & $34(33 \cdot 7)$ & $116.2 \pm 7$ & 0.157 & $74.71 \pm 5.1$ & 0.328 \\
\hline$>40$ years old & $67(66.3)$ & $119.9 \pm 10.7$ & & $75 \cdot 7 \pm 5 \cdot 3$ & \\
\hline \multicolumn{6}{|l|}{ Sex } \\
\hline Female & $4(4)$ & $112.5 \pm 5$ & 0.088 & $72 \cdot 5 \pm 5$ & 0.244 \\
\hline Male & $97(96)$ & $118.9 \pm 9.8$ & & $75 \cdot 5 \pm 5 \cdot 2$ & \\
\hline \multicolumn{6}{|l|}{ Service year } \\
\hline$<5$ years & $2(2)$ & $110 \pm 0$ & 0.141 & $80 \pm 0$ & 0.259 \\
\hline
\end{tabular}




\begin{tabular}{|c|c|c|c|c|c|}
\hline \multirow[t]{2}{*}{ Variables } & \multirow[t]{2}{*}{$\mathbf{n}$} & \multicolumn{2}{|c|}{ SBP } & \multicolumn{2}{|c|}{ DBP } \\
\hline & & Mean \pm SD & P-value* & Mean \pm SD & P-value * \\
\hline $5^{-<10}$ years & $16(15.8)$ & $118.1 \pm 4$ & & $74.4 \pm 5.1$ & \\
\hline $10-<15$ years & $41(40.6)$ & $117 \cdot 3 \pm 7 \cdot 6$ & & $75.1 \pm 5.1$ & \\
\hline >15 years & $42(41.6)$ & $120.5 \pm 12.5$ & & $75 \cdot 7 \pm 5 \cdot 5$ & \\
\hline \multicolumn{6}{|l|}{ Smoking } \\
\hline No & $83(82.2)$ & $118.2 \pm 9.4$ & 0.603 & $75 \cdot 1 \pm 5 \cdot 3$ & 0.243 \\
\hline Yes & $18(17.8)$ & $120.6 \pm 11.1$ & & $76.7 \pm 4.9$ & \\
\hline \multicolumn{6}{|l|}{ Body Mass Index } \\
\hline Underweight & o (o) & o & 0.073 & o & 0.08 \\
\hline Normal weight & $42(41.6)$ & $116.9 \pm 9$ & & $74.8 \pm 5 \cdot 5$ & \\
\hline Overweight & $40(39.6)$ & $119 \pm 10.3$ & & $75 \pm 5.1$ & \\
\hline Obese & $19(18.8)$ & $121.6 \pm 9.6$ & & $77 \cdot 4 \pm 4 \cdot 5$ & \\
\hline \multicolumn{6}{|l|}{ Stress level } \\
\hline Mild & $15(14.9)$ & $118 \pm 5.6$ & 0.746 & $74 \pm 5.1$ & 0.237 \\
\hline Medium & $59(58.4)$ & $118.3 \pm 10.4$ & & $75 \cdot 4 \pm 5.4$ & \\
\hline Severe & $27(26.7)$ & $119.6 \pm 10.2$ & & $75 \cdot 9 \pm 5$ & \\
\hline
\end{tabular}

*P values were calculated by Mann-Whitney test

Noise dose exposure $>80 \mathrm{dBA}$ had higher prevalence of hypertension $7.9 \%(\mathrm{n}=5)$ and $2.6 \%(\mathrm{n}=$ 1) in the subject with noise dose $\leq 80 \mathrm{dBA}$ with $\mathrm{OR}=3.190(95 \% \mathrm{CI}=0.358-28.394)$. Prevalence of hypertension in the subjects with age $>40$ years was $9 \%(\mathrm{n}=6)$ and male was $6.2 \%(\mathrm{n}=6)$. There are $41.6 \%(n=42)$ had $>15$ service years and prevalence of hypertension was $11.9 \%(n=5)$. Prevalence of hypertension was $11.1 \%(\mathrm{n}=2)$ in the subjects with smoking status and $\mathrm{OR}=2.469(95 \% \mathrm{CI}=0.416-14.645)$. Subjects with obese category had higher prevalence of hypertension $10.5 \%$ compared to normal weight and overweight. Stress level with category severe had higher prevalence of hypertension $7.4 \%$. The noise dose effect to the risk of hypertension was shown in Table 3 based on the SBP and DBP.

Table 3. Prevalence and risk factors of hypertension based on SBP and DBP at geothermal company

\begin{tabular}{|c|c|c|c|c|c|}
\hline Variables & $\mathbf{n}$ & $\begin{array}{l}\text { Non- } \\
\text { hypertension }\end{array}$ & Hypertension & Pvalue $^{*}$ & OR $(95 \%$ CI $)$ \\
\hline \multicolumn{6}{|l|}{ Noise dose } \\
\hline$\leq 8 \mathrm{o} \mathrm{dBA}$ & $38(37.6 \%)$ & $37(97.4 \%)$ & $1(2.6 \%)$ & & $3.190(0.358-28.394)$ \\
\hline$>80 \mathrm{dBA}$ & $63(62.4 \%)$ & $58(92.1 \%)$ & $5(7 \cdot 9 \%)$ & 0.405 & \\
\hline \multicolumn{6}{|l|}{ Age } \\
\hline$\leq 40$ years old & $34(33.7 \%)$ & $34(100 \%)$ & o (o\%) & & \\
\hline$>40$ years old & $67(66.3 \%)$ & $61(91 \%)$ & $6(9 \%)$ & 0.095 & \\
\hline \multicolumn{6}{|l|}{ Sex } \\
\hline Female & $4(4 \%)$ & $4(100 \%)$ & o $(0 \%)$ & & \\
\hline Male & $97(96 \%)$ & $91(93.8 \%)$ & $6(6.2 \%)$ & 1,000 & \\
\hline \multicolumn{6}{|l|}{ Service year } \\
\hline$<5$ years & $2(2 \%)$ & $2(100 \%)$ & o (o\%) & & \\
\hline $5^{-<10}$ years & $16(15.8 \%)$ & $16(100 \%)$ & o $(0 \%)$ & 0.194 & \\
\hline $10-<15$ years & $41(40.6 \%)$ & $40(97.6 \%)$ & $1(2.4 \%)$ & & \\
\hline$>15$ years & $42(41.6 \%)$ & $37(88.1 \%)$ & $5(11.9 \%)$ & & \\
\hline \multicolumn{6}{|l|}{ Smoking } \\
\hline No & $83(82.2 \%)$ & $79(95.2 \%)$ & $4(4.8 \%)$ & & $2.469(0.416-14.645)$ \\
\hline Yes & $18(17.8 \%)$ & $16(88.9 \%)$ & $2(11.1 \%)$ & 0.290 & \\
\hline \multicolumn{6}{|l|}{ Body Mass Index } \\
\hline Normal weight & $42(41.6 \%)$ & $41(97.6 \%)$ & $1(2.4 \%)$ & & \\
\hline Overweight & $40(39.6 \%)$ & $37(92.5 \%)$ & $3(7 \cdot 5 \%)$ & 0.398 & \\
\hline Obese & $19(18.8 \%)$ & $17(89.5 \%)$ & $2(10.5 \%)$ & & \\
\hline \multicolumn{6}{|l|}{ Stress level } \\
\hline Mild & $15(14.9 \%)$ & $15(100 \%)$ & o $(0 \%)$ & & \\
\hline Medium & $59(58.4 \%)$ & $55(93.2 \%)$ & $4(6.8 \%)$ & 0.570 & \\
\hline Severe & $27(26.7 \%)$ & $25(92.6 \%)$ & $2(7.4 \%)$ & & \\
\hline
\end{tabular}

${ }^{*} \chi^{2}$ analysis calculated P values 


\section{Discussion}

This study was based on the samples of 101 permanent employees at a geothermal power plant. Contractor employees were not taken as samples because MCU data was not available by the company, and some of them are based on-call basis service. The result showed noise exposure was not associated with blood pressure (SBP and DBP); however, occupational noise exposure with noise intensity $>85 \mathrm{dBA}$ had higher SBP, DBP level and hypertension risk. The mean of SBP and DBP level increase of $1.2 \mathrm{~mm} \mathrm{Hg}$ and $0.6 \mathrm{~mm} \mathrm{Hg}$ compared to noise exposure $\leq 80 \mathrm{dBA}$. The risk of hypertension was 3.19 (95\% CI: 0.358 28.394) compared with exposed $\leq 80 \mathrm{dBA}$. A similar finding from a previous study on the cohort study that noise exposure $\geq 85 \mathrm{dBA}$ had a mean increase of SBP $3.2 \mathrm{~mm} \mathrm{Hg}$, DBP $2.5 \mathrm{~mm}$ Hg and hypertension risk was 1.93 (95\% CI: 1.15-3.22) (Yuan et al., 2013). Another study also showed that workers in steel factories exposed to occupational noise had significant SBP and DBP levels compared to non-exposed subjects. Noise exposure had increased the prevalence of hypertension with OR 2.03 (Zhou et al., 2019).

Some studies on occupational noise and association with SBP, DBP, and/or hypertension have been investigated; however, the results were not consistent (Chen et al., 2017). The cross-sectional study of 90 workers in Isfahan, Iran, showed no significant association between blood pressure and noise level. However, SBP and mean BMI had considerable correlation with correlation coefficient $=0.422$ and pvalue $<0.01$ (Rizi, 2012). Chronic exposure to noise intensity may disturb the unbalanced of organism homeostatic that affects metabolism and cardiovascular system, increase blood pressure, blood lipid, blood glucose concentration, and viscosity of blood (Ohrstrom E, 2006). Noise exposure has an indirect pathway involving cognitive perception and emotional response to noise that lead to stress response triggering heart rate alteration and vasoconstriction via sympathetic and endocrine stress response such as sleep disturbance and annoyance associated with cardiovascular disease (Daiber et al., 2019). These changes increase the risk of hypertension, myocardial infarction, and stroke (Basner et al., 2014). There was a dose-effect association between cumulative noise exposure and the risk of hypertension (Jiahui et al., 2018). There is still no consensus among scientists on the noise exposure leads to increased blood pressure and hypertension (Kim \& Ahn, 2021). A study in Taiwan showed that noise intensity $>80 \mathrm{dBA}$ had an association with hypertension (Chang et al., 2012). Another study from 4,548 participants showed no consistent association between noise exposure with blood pressure and hypertension (Gan \& Mannino, 2018).

This study showed service years and SBP, DBP and hypertension were not associated (p-value $>0.05$ ). A similar study showed that length of service years was not associated with blood pressure (Stefani et al., 2018; Sancini et al., 2014). Individual characteristics (age, sex, BMI) and smoking status were not associated with SBP, DBP and hypertension (p-value >0.05). Another study from Indriyanti (2019) also showed that BMI was not associated with blood pressure $(\mathrm{p}$-value $=0.114)$. Workers with service years $\geq 15$ years had OR 4.055 higher than workers with service $<1$ year and found that age had no association (pvalue $=0.941$ ) while smoking status had an association (p-value $<0.001$ ) (Chen et al., 2017). Workers who had service years $>15$ years at this geothermal company was $41.6 \%$, and service years $10-<15$ years was $40.6 \%$ from total participants. Workers with longer service years had the potential of higher cumulative noise exposure (CNE). The study result showed a cumulative effect on hypertension due to CNE (Li et al., 2018).

Stress level showed no association with SBP, DBP and hypertension ( $p$-value $>0.05$ ). However, workers with higher stress levels had higher SBP and DBP levels. Worker with severe stress category (prevalence of hypertension $=7.4 \%$ ) slightly higher than medium stress $(6.8 \%)$ and mild stress $(0 \%)$. Noise exposure results in endocrine signalling and the autonomous nervous system that causes mental stress (Hahad et al., 2019). Based on the study of animals, rats exposed to noise 80-10o dBA had increased stress hormone and causing in oxidative stress (Said et al., 2016). Noise exposure can cause sleep \& communication disturbance that leads to the sympathetic nervous system (causing catecholamine release) and endocrine stress response and affect blood pressure increase that generates cardiovascular 
disease for a prolonged period (Daiber et al., 2019). Noise exposure affects stress hormone release, oxidative stress, vascular dysfunction, and inflammation that lead to blood viscosity, vascular function, and hypertension (Daiber et al., 2019). The amygdala, a region part of the brain associated with stress perception and emotional processes, is involved in stress response due to noise exposure and this metabolic activity was associated with cardiovascular disease risk involving arterial inflammation increase (an increase of amygdala activity associated with higher noise exposure) (Osborne et al., 2020).

The study result showed no association between noise intensity and blood pressure (SBP, DBP, and hypertension). However, the workers exposed to noise intensity $>80 \mathrm{dBA}$ had higher blood pressure levels, higher prevalence of hypertension, and increased risk of hypertension with OR 3.19 compared to those exposed to noise intensity $\leq 80 \mathrm{dBA}$. Linear regression analysis showed that variable sex was the dominant risk factor for SBP and DBP at the geothermal power plant. The male workers are prevalent at this geothermal company, with $96 \%$ of the total 101 participants and workers who had hypertension. Previous studies with a larger sample size with a total of 2,789 participants from the control and an exposed group showed that noise intensity had an association with blood pressure (SBP \& DBP) and hypertension (Chen et al., 2017). Another study in steel factories from 1,874 workers also showed an association between noise exposure and blood pressure with a p-value $<0.001$ (Zhou et al., 2019). This pilot study provided baseline data on hypertension prevalence and the association of noise intensity with blood pressure and hypertension in geothermal power plants. We recommended that further research have a larger sample size with a random sampling method and balance sample from the exposed and control groups to investigate the association between noise intensity and blood pressure.

This study has some limitations. First, the sampling method was purposive sampling, not a random sampling, due to no MCU data of contractor's employees kept by geothermal company. So, it cannot represent the population of geothermal workers. Participants are only permanent employees, while contractors' employees are excluded. A higher number of participants and random sampling will be better to investigate the association of noise intensity and SBP, DBP and hypertension. The second limitation is that we have not investigated whether the workers with hypertension consume antihypertension drug so their SBP and DBP level can be maintained in the average range level. This study was only reviewed based on the MCU result from a geothermal company.

\section{Conclusion}

Occupational noise exposure had no significant association with blood pressure (SBP and DBP) and risk of hypertension. However, there was a dose-response relationship between noise dose and SBP, DBP, and hypertension. The SBP showed more sensitivity to occupational noise exposure, with the mean of SBP level increase being higher than DBP. Workers exposed to noise intensity $>80 \mathrm{dBA}$ had a higher risk of hypertension with OR 3.19. This study is a start to investigate the association between noise intensity and SBP, DBP and hypertension at the geothermal power plant. The opportunity to explore the association between these variables are needed. We suggested controlling noise exposure to geothermal workers to reduce the risk of hypertension and continue implementing a hearing conservation program.

\section{Ethical Clearance}

This study has been endorsed by The Research and Community Engagement Ethical Committee of Faculty of Public Health Universitas Indonesia No. Ket-417/UN2.F1o.D11/PPM.oo.02/2021.

\section{References}

Anju, S., Setiani, O., Dangiran, H. 2018. Hubungan Intensitas Kebisingan dan Masa Kerja dengan Peningkatan Tekanan Darah pada Pekerja Polyester PT Indonesia Toray Synthetics Kota Tangerang. Jurnal Kesehatan Masyarakat 6 (4), 402-408.

Barton, B., Peat, J. 2014. Medical Statistics: A Guide to SPSS, Data Analysis and Critical Appraisal - Second 
Edition. West Sussex: Blackwell Publishing Ltd.

Basner, M., Babisch, W., Davis, A., Brink, M., Clark, C., Janssen, S., Stansfeld, S. 2014. Auditory and NonAuditory Effects of Noise on Health. Lancet 383, 1325-1332.

Chang, T., Hwang, B., Liu, C., Chen, R., Wang, V., Bao, B., Lai, J. 2013. Occupational Noise Exposure and Incident Hypertension in Men: A Prospective Cohort Study. American Journal of Epidemiology 177 (8), 818-825.

Chang, T., Liu, C., Young, L., Wang, V., Jian, S., Bao, B. 2012. Noise frequency components and the prevalence of hypertension in workers. The Science of the Total Environment 416, 89-96.

Chen, S., Ni, Y., Zhang, L., Kong, L., Lu, L., Yang, Z., Yang, L., Zhang, X., Zhu, Y. 2017. Noise exposure in occupational setting associated with elevated blood pressure in China. BMC Public Health, 17(1), 107.

Daiber, Andreas., et al. 2019. Environmental Noise Induces the Release of Stress Hormone and Inflammatory Signaling Molecules Leading to Oxidative Stress and Vascular Dysfunction Signatures of the Internal Exposome. International Union of Biochemistry and Molecular Biology 45 (4), 495-506.

De Souza, T. C., Périssé, A. R., Moura, M. 2015. Noise exposure and hypertension: Investigation of a silent relationship. BMC Public Health, 15(1), 328.

Direktorat Jenderal Energi Baru, Terbarukan, dan Konservasi Energi (Ditjen EBTKE). 2021. Laporan Kinerja Ditjen EBTKE Tahun 2020. Jakarta: The Ministry of Energy and Mineral Resources Republik Indonesia.

Gan, W., Mannino, D. 2018. Occupational Noise Exposure, Billateral High-Frequency Hearing Loss, and Blood Pressure. Journal of Occupational and Environmental Medicine 6o (5), 462-468.

Hahad, O., H.Prochaska, J., Daiber, A., Thomas, M. 2019. Environmental Noise-Induced Effects on Stress Hormones, Oxidative Stress, and Vascular Dysfunction: Key Factors in Relationship between Cerebrocardiovascular and Psychological Disorders. Hindawi Oxidative Medicine and Cellular Longevity, 1-13.

Indriyanti, L., Wangi, P., Simanjuntak, K., 2019. Hubungan Paparan Kebisingan terhadap Peningkatan Tekanan Darah pada Pekerja. Jurnal Kedokteran dan Kesehatan 15 (1), 36-45.

Kim, M., Ahn, Y. 2021. The Relationship Between Occupational Noise Exposure and Hypertension Using Nearest Age-Matching Method in South Korea Male Workers. Cogent Engineering 8 (1), 1-10.

Li, J., Tao, Z., Huang, L., Zhang, J., Rong, X., Wang, Z., 2018. Effect of Cumulative Noise Exposure on Hypertension in Automotive Manufacturing Workers. China Occupational Medicine 6, 173-177.

Munzel, T., et al. 2016. Environmental Stressors and Cardio-Metabolic Disease: Part II-Mechanistic Insights. European Heart Journal 38 (8), 557-564.

Ohrstrom, E., Skanberg, A., Svensson, H., Gidlof-Gunnarsson, A., 2006. Effects of Road Traffic Noise and the Benefit of Access to Quietness. Journal of Sound Vibration 295, 40-59.

Osborne, M., et al. 2020. A Neurobiological Mechanism Linking Transportation Noise to Cardiovascular Disease in Humans. European Heart Journal 41, 772-782.

Prasetyo, S., Ariawan, I. 20o8. Biostatistik Dasar untuk Rumah Sakit. Depok: Departement Kependudukan dan Biostatistik FKM UI.

Rizi, H., Dehghan, H. 2012. Effects of Occupational Noise Exposure on Changes in Blood Pressure of Workers. ARYA Atherosclerosis Journal 8, S183-S186.

Said, MA., El-Gohary, OA. 2016. Effect of Noise Stress on Cardiovascular System in Adult Male Albino Rat: Implication of Stress Hormones, Endothelial Dysfunction and Oxidative Stress. General Physiology and Biophysics 35 (03), 371-377.

Sancini, A., Caciari, T., Rosati, MV., Samperi, i., Iannattone, G., Massimi, R., Loreti, B., Scala, B., Sacco, C., Tomei, F.,Tomei, G. 2014. Can Noise Cause High Blood Pressure? Occupational Risk in Paper Industry. Clin Ter 165 (4), 304e-311e.

Sheppard, A., Ralli, M., Gilardi, A., Salvi, R. 2020. Occupational Noise: Auditory and Non-Auditory Consequences. International Journal of Environmental Research and Public Health 17 (8963), 1-15. 
Muhyidin and Nasri., 2021. Analysis of Occupational Noise in Association with Blood Pressure Among Workers at Geothermal Power Plant

J. Presipitasi, Vol 18 No 3: 504-511

Zhou, F., Shrestha, A., Mai, S., Tao, Z., Li, J., Wang, Z., Meng, X. 2019. Relationship Between Occupational Noise Exposure and Hypertension: A Cross-Sectional Study in Steel Factories. American Journal of Industrial Medicine 62, 961-968. 